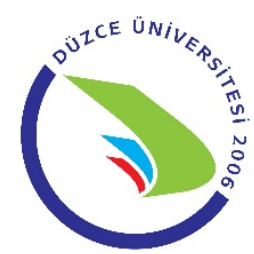

\title{
Özel Bakım Gereksinimi Olan Bireylerde Ağız-Diş Bulgularının Değerlendirilmesi
}

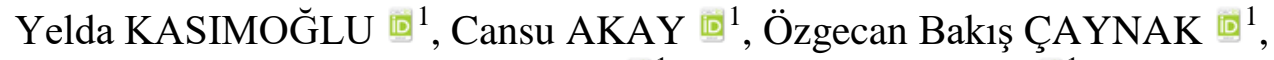 \\ Fatma Zeynep AYTEPE [0] $^{1}$, Mine KORUYUCU ${ }^{1}$
}

\section{ÖZ}

Amaç: Özel bakım gereksinimi olan çocuklarda ağız sağlığı problemleri, genel sağlık sorunlarına ek olarak ortaya çıkan büyük bir sağlık sorunudur. Bu çalışmanın amacı, İstanbul ilinde özel eğitim veren okullarda muayene edilen özel bakım gereksinimi olan bireylerin ağız-diş sağlığı verilerinin değerlendirilmesidir.

Gereç ve Yöntemler: Bu kesitsel çalışma İstanbul Üniversitesi Diş Hekimliği Fakültesi Pedodonti Anabilim Dalı ile İstanbul Üniversitesi Diş hekimliği Fakültesi Engelsiz Gülüşler Öğrenci Kulübü sosyal sorumluluk projesi olarak İstanbul ili içerisinde özel eğitim veren okullarda gerçekleştirildi. Ağız ve diş sağlığı taramaları için her bir tarama öncesi özel olarak izin alındı. Ağız muayenesi gün ışığında tek kullanımlık ayna, sond ve presel yardımı ile yapıldı. Muayenede çocukların yaşları, engel durumları, ilaç kullanıp kullanmadıkları, diş çürüğü varlığı, dental travma varlığı, diş sıkma ve maloklüzyon durumları kaydedildi. Verilerin değerlendirilmesinde uygun istatistiksel testler/analizler kullanıldı ve anlamlılık düzeyi 0,05 olarak belirlendi.

Bulgular: 42'sinde otizm, 111'inde mental retardasyon ve 10'unda Down sendromu olmak üzere 163 özel bakım gereksinimi olan bireyin ağız içi muayenesi yapıldı. Her üç grubun DMFT ve dft ortalamaları arasında istatistiksel olarak anlamlı bir fark bulunmadı $(\mathrm{p}>0,05)$. Down sendromlu bireylerde nötral oklüzyon görülme oranı, otizmli bireylerden daha düşük bulundu $(\mathrm{p}<0,05)$. Sınıf II maloklüzyon için gruplar arası fark görülmezken, Sınıf III maloklüzyon görülme oranının zihinsel engellilerde otizmlilere göre daha yüksek, Down sendromlu bireylerde hem zihinsel engelli bireylerden hem de otizmli bireylerden daha yüksek olduğu görüldü $(\mathrm{p}<0,05)$.

Sonuç: Özel bakım gereksinimi olan bireylerin diş çürükleri, maloklüzyon, dişlerde aşınma, bruksizm, dental travma ve ağız-diş sağlığı açısından takip edilmeleri ve ağız-diş sağlığı açısından yakından takip edilmeleri gerekmektedir.

Anahtar Kelimeler: Engelli çocuklar; engelliler için diş hekimliği; Down sendromu; otizm; zihinsel engelli.

\section{Evaluation of Oral-Dental Findings in Individuals with Special Care Needs}

\begin{abstract}
Aim: Oral health problems in children with special care needs are a major health problem that occurs in addition to general health problems. The aim of this study is to evaluate the oral and dental health data of individuals with special care needs examined in schools providing special education in Istanbul.

Material and Methods: This cross-sectional study was carried out at Istanbul University Faculty of Dentistry Department of Pedodontics and Istanbul University Faculty of Dentistry Disable-Free Smile Student Club as a social responsibility project in schools providing special education in Istanbul special permissions were obtained before each screening for oral and dental health. Oral examination was done with the help of disposable dental mirror, explorer probe and cotton plier in daylight. In the examination, the ages of the children, their disability, whether they used drugs, the presence of dental caries, the presence of dental trauma, bruxism and malocclusion were recorded. Appropriate statistical tests/analyzes were used to evaluate the data and the level of significance was set to be 0.05 .

Results: Intraoral examination of individuals with 163 special care needs including 42 autism, 111 mental retardation and 10 Down syndrome was performed. There was no statistically significant difference between the DMFT and dft averages of all three groups ( $>0.05$ ). Neutral occlusion rate was lower in individuals with Down syndrome than in
\end{abstract}

1 İstanbul Üniversitesi, Diş Hekimliği Fakültesi, Pedodonti AD, İstanbul, Türkiye

Sorumlu Yazar / Corresponding Author: Yelda KASIMOĞLU, e-mail: yelda.kasimoglu@istanbul.edu.tr Geliş Tarihi / Received: 22.01.2020, Kabul Tarihi / Accepted: 22.06.2020 
individuals with autism and people with intellectual disabilities $(\mathrm{p}<0.05)$. There was no statistically significant difference between Class II occlusion rates of all three groups ( $>0.05$ ). It was found that the frequency of Class III relationship was higher in individuals with Down syndrome than individuals with mental retardation and autism. Also it was higher in individuals with mental retardation than individuals with autism $(p<0.05)$.

Conclusion: Individuals with special care needs should be followed in terms of dental caries, malocclusion, erosive tooth loss, bruxism and dental trauma and should be followed closely for oral and dental health.

Keywords: Disabled children; dentistry for disabled; Down syndrome; autism; mentally handicapped.

\section{GÍRIS}

Amerikan Sağlık Birliği (The American Health Association) tarafından çocuklarda engellilik; "Bir çocuğun çeşitli nedenlerle fiziksel, mental ve sosyal becerilerini tam olarak gerçekleştirememesi; oyun oynayamaması, öğrenememesi, kendi yaşıtlarının yaptıklarını yapamaması" olarak tanımlanmaktadır. Bu çocuklar fiziksel, mental, duyusal, davranışsal, duygusal ve kronik tıbbi durumlarından ötürü yaşam boyu rutin olarak desteğe ihtiyaç duymalarından dolayı "özel bakım gereksinimi olan çocuklar” olarak da adlandırılmaktadırlar (1).

Başbakanlık Özürlüler İdaresi Başkanlığı'nın 2006 yılında yayınladığı araştırma sonuçlarına göre ülkemiz toplam nüfusunun \%12,29'unu özel bakım gereksinimi olan bireyler oluşturmaktadır. $\mathrm{Bu}$ oranın \%2,58'lik kısmını (yaklaşık 1,8 milyon) ortopedik, görme, işitme, dil ve konuşma ile zihinsel engelliler oluşturmaktadır (2). Özel bakım gereksinimi olan çocuklarda ağız sağlığ problemleri, genel sağlık sorunlarına ek olarak ortaya çıkan büyük bir sağlık sorunudur. Literatürde özel bakım gereksinimi olan bireylerin daha kötü ağız hijyenine sahip oldukları, çürük prevalanslarının yüksek olduğu, tedavi edilmemiş diş çürüklerinin fazla olduğu ve diş eksikliğinin daha çok olduğu rapor edilmiştir (3). Özel bakım gereksinimi olan bireylerin motor, duyu ve entelektüel engellerinden dolayı ağı hijyeni uygulamalarının zayıf olduğu ve kötü ağız hijyenine eğilimli oldukları bildirilmektedir. $\mathrm{Bu}$ bireylerin özel durumları, ağız-diş sağlığı konusunda bilgi edinmelerini kisitlamakta, aralarında siklikla dental anksiyeteye rastlanmakta ve kötü ağız hijyenine sahip oldukları görülmektedir (4).

Bu çalışmanın amacı, İstanbul ilinde özel eğitim veren okullarda muayene edilen özel bakım gereksinimi olan 163 bireyin ağız-diş sağlığ1 verilerinin değerlendirilmesidir.

\section{GEREÇ VE YÖNTEMLER}

$\mathrm{Bu}$ kesitsel çalışma, İstanbul Üniversitesi Diş Hekimliği Fakültesi Pedodonti Anabilim Dalı ile İstanbul Üniversitesi Diş hekimliği Fakültesi Engelsiz Gülüşler Öğrenci Kulübü sosyal sorumluluk projesi olarak İstanbul ili içerisinde 1.09.2017-01.06.2018 tarihleri arasında özel eğitim veren okullarda gerçekleştirildi. Ağız ve diş sağlığı taramaları için İstanbul Üniversitesi Diş Hekimliği Fakültesi Klinik Araştırmalar Etik Kurulundan (2016/21) ve İstanbul Milli Eğitim Bakanlığı'ndan her okul için özel olarak izin alındı. Çalıșma sırasında veriler araștırma ve yayın etiğine uygun bir şekilde topland. Özel bakım gereksinimi olan bireylere özel eğitim veren iki okulda gerçekleştirilen tarama çalışmasında ailelerinden onam alındıktan sonra özel bakım gereksinimi olan çocuklar muayene edildi ve özel bakım gereksinimi olan bireyler ile ailelerine ve öğretmenlerine ağız-diş bakımıyla ilgili eğitim verildi. Engelli bireyler gelişigüzel örnekleme yöntemi ile çalışmaya dahil edildi.

Ağız muayenesi gün 1şığında tek kullanımlık ayna, sond ve presel yardımı ile yapıldı. Muayenede çocukların yaşları, engel durumları, ilaç kullanıp kullanmadıkları, diş çürüğ̈ varlığ 1 , dental travma varlığı, diş sıkma ve maloklüzyon durumları kaydedildi.

Diş çürüğü muayenesi için çürük-çekilmiş-dolgulu diş (kalıcı dişler için DMFT, süt dişleri için dmft) indeksi kullanıldı (5). Maloklüzyon muayenesi, Angle sınıflamasına göre yapıldı. Bu sınıflamaya göre Sınıf I kapanış üst birinci büyük azı dişinin mesio-bukkal tüberkülünün alt 1 . büyük azı dişinin mesio-bukkal sulkusuna oturduğu nötral oklüzyondur. Sınıf II kapanış ilișkisinde azı kapanıșı distal pozisyondadır, üst çene ve alt çene kaideleri birbirlerine ve kafa kaidesine göre normal ilişkide değildirler. Sınıf III kapanış ilişkisinde ise alt çene aşırı gelişmiş ya da üst çene az gelişmiştir, her ikisinin kombinasyonu da söz konusu olabilmektedir (6).

\section{İstatistiksel Analiz}

İstatistiksel değerlendirme için SPSS 20.0 paket programı kullanıldı. Çalışmaya katılan özel bakım gereksinimi olan bireylerin yaş, cinsiyet ve engel durumu hakkında tanımlayıcı istatistikleri hesaplandı. Bireylere ait yaş, engel durumu, cinsiyet, sistematik hastalık, ilaç kullanımı, diş sıkma, aşınma, malokluzyon, travma varlığı ve diş çürüğü verileri üzerinden çeşitli oran ve ortalama karşılaştırmaları yapıldı. Veriler analiz edilirken kategorik veriler için Pearson Ki Kare testi kullanıldı. Ancak çapraz tablo hücrelerinde beklenen değerinin en az 5 olma varsayımının sağlanamadığı durumlarda Likelihood Ratio test istatistiğinden faydalanıldı. Anlamlı fark görülen çoklu karşılaştırmalarda post hoc test olarak, SPSS programındaki Bonferroni düzeltmeli $\mathrm{z}$ oran testi yapıldı. Sürekli veriler için önce verilerin normal dağılıp dağılmadığını tespit etmek amacıyla Shapiro-Wilk testinden yararlanıldı. DMFT değişkeni için normal dağılım gözlemlenmemesi sebebiyle Kruskal Wallis analizi kullanılırken, dft değişkeni için ise normal dağılıma uygunluğa karşın düşük örneklem sayısı $(\mathrm{n}<30)$ sebebi ile Mann-Whitney $U$ testi tercih edildi. Tüm analizlerde anlamlılık düzeyi 0,05 olarak belirlendi.

\section{BULGULAR}

Çalışmaya katılan özel bakım gereksinimi olan bireylerin yaş ortalaması 14,89 $\pm 3,14$ 'tür. Toplam 163 özel bakım gereksinimi olan bireyin 58'i k1z, 105'i erkektir. Katılımciların 42'sinde $(\% 25,77)$ otizm, 111'inde $(\% 68,10)$ mental retardasyon ve 10'unda ise $(\% 6,13)$ Down sendromu mevcuttur (Tablo 1).

Dental travma açısından kızlar ve erkekler arasında istatistiksel olarak anlamlı bir fark bulunmamaktadır ( $>>0,05)$. Dental travma sıklığı ve engellilik tipi arasında istatistiksel olarak anlamlı bir ilişki bulunmamaktadır ( $>0,05)$ (Tablo 2). 
Tablo 1. Çalışmada kullanılan demografik veriler $(n=163)$

\begin{tabular}{|l|c|c|}
\hline Değişken & Ortalama & Standart Sapma \\
\hline Yaş & 14,89 & 3,14 \\
\hline Cinsiyet & $\mathbf{n}$ & $\mathbf{\%}$ \\
\hline Kiz & 58 & 35,6 \\
\hline Engek Durumu & 105 & 64,42 \\
\hline Otizm & $\mathbf{n}$ & $\mathbf{\%}$ \\
\hline Zihinsel Engelli & 12 & 25,77 \\
\hline Down Sendromu & 11 & 68,10 \\
\hline
\end{tabular}

n: Katılımc1 sayıs1

Tablo 2. Cinsiyete ve engel türüne göre travma sıklığının karşılaştırılması $(\mathrm{n}=163)$

\begin{tabular}{|c|c|c|c|c|}
\hline & \multicolumn{2}{|c|}{ Travma Varlığı n(\%) } & \multirow[b]{2}{*}{$\begin{array}{c}\text { Test } \\
\text { Değeri }\end{array}$} & \multirow[b]{2}{*}{$\mathbf{p}$} \\
\hline & Yok & Var & & \\
\hline \multicolumn{5}{|l|}{ Cinsiyet } \\
\hline Kız & $\begin{array}{c}49 \\
(\% 84,48)\end{array}$ & $\begin{array}{c}9 \\
(\% 15,52)\end{array}$ & \multirow{2}{*}{0,966} & \multirow{2}{*}{0,326} \\
\hline Erkek & $\begin{array}{c}82 \\
(\% 78,1)\end{array}$ & $\begin{array}{c}23 \\
(\% 21,9) \\
\end{array}$ & & \\
\hline \multicolumn{5}{|l|}{ Engel Durumu } \\
\hline Otizm & $\begin{array}{c}36 \\
(\% 85,71)\end{array}$ & $\begin{array}{c}6 \\
(\% 14,29)\end{array}$ & \multirow{3}{*}{1,040} & \multirow{3}{*}{0,594} \\
\hline Zihinsel engelli & $\begin{array}{c}87 \\
(\% 78,38)\end{array}$ & $\begin{array}{c}24 \\
(\% 21,62)\end{array}$ & & \\
\hline $\begin{array}{c}\text { Down } \\
\text { Sendromu }\end{array}$ & $\begin{array}{c}8 \\
(\% 80) \\
\end{array}$ & $\begin{array}{c}2 \\
(\% 20) \\
\end{array}$ & & \\
\hline
\end{tabular}

Bruksizm açısından, düzenli olarak ilaç kullanan ve ilaç kullanmayanların arasında istatistiksel olarak anlamlı bir fark bulunmamaktadır ( $>00,05)$. Diş yüzeylerinde görülen aşınmalar açısından düzenli olarak ilaç kullanan ve ilaç kullanmayan arasında istatistiksel olarak anlamlı bir fark bulunmaktadır $(\mathrm{p}<0,05)$. Düzenli olarak ilaç kullanan özel bakım gereksinimi olan bireylerin dişlerinde aşınma görülme oranı ilaç kullanmayanlardan daha düşüktür (Tablo 3).

Tablo 3. İlaç kullanımına göre bruksizm ve aşınmanın karşılaștırılması $(\mathrm{n}=163)$

\begin{tabular}{|c|c|c|c|c|}
\hline \multirow{2}{*}{ Bruksizm } & İlaç kullanımı n (\%) & \multirow{2}{*}{$\begin{array}{c}\text { Test } \\
\text { Değeri }\end{array}$} & \multirow{2}{*}{ p } \\
\cline { 2 - 3 } Yok & $\begin{array}{c}63 \\
(\% 56,76)\end{array}$ & $\begin{array}{c}37 \\
(\% 71,15)\end{array}$ & \multirow{2}{*}{3,095} & \multirow{2}{*}{0,079} \\
\hline Var & $\begin{array}{c}48 \\
(\% 43,24)\end{array}$ & $\begin{array}{c}15 \\
(\% 28,85)\end{array}$ & & \\
\hline Aşınma & \multicolumn{3}{|c|}{} & \multirow{2}{*}{$0,015^{*}$} \\
\hline Yok & $\begin{array}{c}66 \\
(\% 59,46)\end{array}$ & $\begin{array}{c}41 \\
(\% 78,85)\end{array}$ & \multirow{2}{*}{5,901} & \\
\hline \multicolumn{2}{|c|}{ Var } & $\begin{array}{c}45 \\
(\% 40,54)\end{array}$ & $\begin{array}{c}11 \\
(\% 21,15)\end{array}$ & \\
\hline
\end{tabular}

Pearson Ki Kare Testi, n: Katılımcı sayısı

Çenelerin kapanış ilişkisi değerlendirildiğinde; maloklüzyon oranlarının engel tipine göre farklı olduğu görülmüştür $(p<0,05)$. Down sendromlu bireylerde Sınıf I maloklüzyon görülme oranı, otizmli ve zihinsel engelli bireylerden daha düşük bulunmuştur $(p<0,05)$. Sinıf II kapanış ilişkisi açısından üç engel grubu arasında herhangi bir farklılık gözlenmemiştir $(p>0,05)$. Down sendromlu bireylerin yarısında Sinıf III maloklüzyon görülürken, zihinsel engelli bireylerde bu oran $\% 14,41$ 'dir. Otizmli bireylerde ise Sinıf III maloklüzyona rastlanmamıştır. Üç grupta Sınıf III maloklüzyon görülme oranlarının tamamı istatistiksel olarak birbirlerinden farklıdır $(\mathrm{p}<0,05)$ (Tablo 4).

Tablo 4. Engel tipine ve travma varlığına göre maloklüzyonun karşılaştırılması $(\mathrm{n}=163)$

\begin{tabular}{|c|c|c|c|c|c|}
\hline & \multicolumn{3}{|c|}{ Maloklüzyon n(\%) } & \multirow{2}{*}{$\begin{array}{c}\text { Test } \\
\text { Değeri }\end{array}$} & \multirow[b]{2}{*}{$\mathbf{p}$} \\
\hline & Sinıf I & Sinıf II & Sinıf III & & \\
\hline \multicolumn{6}{|c|}{ Engel Durumu ${ }^{1}$} \\
\hline Otizm & $\begin{array}{c}34 \\
(\% 80,95)^{\mathrm{a}}\end{array}$ & $\begin{array}{c}8 \\
(\% 19,05)^{a} \\
\end{array}$ & $\begin{array}{c}0 \\
(\% 0)^{\mathrm{a}}\end{array}$ & \multirow{3}{*}{21,746} & \multirow{3}{*}{$<0,001$} \\
\hline $\begin{array}{l}\text { Zihinsel } \\
\text { Engelli }\end{array}$ & $\begin{array}{c}69 \\
(\% 62,16)^{\mathrm{a}}\end{array}$ & $\begin{array}{c}26 \\
(\% 23,42)^{\mathrm{a}}\end{array}$ & $\begin{array}{c}16 \\
(\% 14,41)^{\mathrm{b}}\end{array}$ & & \\
\hline $\begin{array}{c}\text { Down } \\
\text { Sendromu }\end{array}$ & $\begin{array}{c}2 \\
(\% 20)^{b}\end{array}$ & $\begin{array}{c}3 \\
(\% 30)^{\mathrm{a}}\end{array}$ & $\begin{array}{c}5 \\
(\% 50)^{\mathrm{c}}\end{array}$ & & \\
\hline \multicolumn{6}{|c|}{ Travma Varlığg ${ }^{2}$} \\
\hline Yok & $\begin{array}{c}83 \\
(\% 63,36)\end{array}$ & $\begin{array}{c}29 \\
(\% 22,14)\end{array}$ & $\begin{array}{c}19 \\
(\% 14,5)\end{array}$ & \multirow{2}{*}{1,569} & \multirow{2}{*}{0,456} \\
\hline Var & $\begin{array}{c}22 \\
(\% 68,75)\end{array}$ & $\begin{array}{c}8 \\
(\% 25) \\
\end{array}$ & $\begin{array}{c}2 \\
(\% 6,25) \\
\end{array}$ & & \\
\hline
\end{tabular}

${ }^{1}$ Likelihood Ratio Testi, ${ }^{2}$ Pearson Ki Kare testi, ${ }^{a, b, c}$ Aynı sütun üzerinde aynı harflerin bulunduğu hücrelerin oranları 0,05 (Bonferroni düzeltmesi) anlamlılık düzeyinde birbirinden farklı değildir, n: Katılımcı sayısı, Sınıf I: Nötroklüzyon, Sınıf II: Distoklüzyon, Sınıf III: Mesioklüzyon

Engel tipinde göre diş çürüğü bulunan, dolgulu veya çekilmiş diş sıklığı incelendiğinde, değerlerin normal dağılmadığı belirlenmiştir. Her üç grubun DMFT ve $\mathrm{dft}$ ortalamaları arasında istatistiksel olarak anlamlı bir fark bulunmamaktadır $(\mathrm{p}>0,05)$ (Tablo 5). DMFT için ortalama rank değerleri otizmli bireyler için 79,87, zihinsel engelli bireyler için 81,93 ve Down sendromlu bireyler için 91,7 olarak bulundu. Süt dişleri için ise $\mathrm{dft}$ ortalama rank değerleri otizmli çocuklarda 14,7 ve zihinsel engelli çocuklarda 1

Tablo 5. Engellilik tipine göre DMFT ve dft ortalamalarının karşılaştırılması

\begin{tabular}{|c|c|c|c|c|c|}
\hline & \multicolumn{3}{|c|}{ DMFT $^{1}$} & \multirow[b]{2}{*}{$\begin{array}{c}\text { Test } \\
\text { Değeri }\end{array}$} & \multirow[b]{2}{*}{$\mathbf{p}$} \\
\hline Engel tipi & Ort \pm SS & Medyan & $\begin{array}{c}\text { Ortalama } \\
\text { Rank }\end{array}$ & & \\
\hline Otizm & $4,17 \pm 1,87$ & 3,92 & 79,87 & \multirow{3}{*}{0,631} & \multirow{3}{*}{0,730} \\
\hline $\begin{array}{l}\text { Zihinsel } \\
\text { Engelli }\end{array}$ & $4,15 \pm 1,90$ & 3,99 & 81,93 & & \\
\hline $\begin{array}{l}\text { Down } \\
\text { Sendromu }\end{array}$ & $4,20 \pm 1,93$ & 4,25 & 91,70 & & \\
\hline & \multicolumn{3}{|c|}{$\mathrm{dft}^{2}$} & & \\
\hline Engel tipi & (Ort $\pm S S)$ & Medyan & $\begin{array}{c}\text { Ortalama } \\
\text { Rank }\end{array}$ & $\begin{array}{c}\text { Test } \\
\text { Değeri }\end{array}$ & $\mathbf{p}$ \\
\hline Otizm & $3,47 \pm 2,53$ & 3,25 & 14,70 & \multirow[b]{2}{*}{100,50} & \multirow[b]{2}{*}{0,847} \\
\hline $\begin{array}{l}\text { Zihinsel } \\
\text { engelli }\end{array}$ & $3,64 \pm 2,47$ & 3,50 & 15,32 & & \\
\hline
\end{tabular}

${ }^{1}$ Kruskal Wallis Analizi, ${ }^{2}$ Mann-Whitney U Testi, Ort: Ortalama Değer, SS: Standart Sapma, DMFT: Daimi dişlerde çürük (D), eksik (M) ve dolgulu (F) diş sayısı (T) toplamı, dft: Süt dişlerinde diş çürük (d) ve dolgulu (f) diş sayısı (t) toplamı

\section{TARTISMA}

Özel bakım gereksinimi olan bireylerin genel popülasyona göre ağız bakımlarını karşılamada zihinsel 
ya da fiziksel olarak zorluk yaşamaları dolayısıyla ağız bakımı açısından desteklenmelerini gerektirmektedir (7). Diş çürüğü sayısının fazlalığı, çürük nedeni ile diş kaybı, periodontal hastalıklar, bruksizme bağlı dişlerde aşınmalar, travma kaynaklı diş kırıkları ve maloklüzyon engelli bireylerin ağız sağlığı problemlerinin başında gelmektedir (8).

\section{Diş Çürüğü}

$\mathrm{Bu}$ çalışmada diş çürüklerinin muayenesinde Dünya Sağlık Örgütü standartlarına göre hazırlanan DMFT indeksi kullanılmıştır (5). Bu yöntemde kaviteleşmiş diş çürükleri etkili bir şekilde tanımlanabilirken, kaviteleşmemiş diş çürüğü lezyonları teşhis edilememektedir (9). Kaviteleșmemiş diș çürüklerinin de çalışmanın yöntemine dahil edilmesi, bu gruptaki bireylerin tedavi ihtiyaçlarının daha iyi anlaşılabilmesini sağlayacağı düşüncesindeyiz. $\mathrm{Bu}$ çalışmada DMFT indeksi; ICDAS'a göre kullanımının daha basit olması, epidemiyolojik çalışmalarda halen standart yöntem olarak kullanılması, diğer ulusal ve uluslararası çalışmalar ile karşılaştırma yapılabilmesine olanak tanıması açısından tercih edilmiştir. Ayrıca ağız-diş muayenelerinin bireylerin kendi yaşam alanlarında yapılması, kaviteleşmemiş diş çürüğü lezyonlarının radyografik muayenesinin yapılmasının hem etik hem pratik açıdan olanaksız olması nedeni ile de DMFT indeksinin kullanılması uygun görülmüştür.

Down sendromlu çocuklarda diş çürüğü prevalansı üzerine literatürde çelişkili veriler mevcuttur. Bazı çalışmalarda sağlıklı bireyler ile karşılaştırıldığında Down sendromlularda diş çürüğüne daha az rastlandığ (10), bazı çalışmalarda ise Down sendromluların diş çürügüüün sağlıklı bireylere benzer ya da daha yüksek olduğunu göstermektedir $(11,12)$. Yapılan bir sistematik derlemede, dahil edilen 13 çalışmadan 10'unda Down sendromluların sağlıklı bireylerden düşük çürük riskine sahip olduğu, 3'ünde ise aralarında herhangi bir fark bulunmadığ 1 sonucu elde edilmiştir (13). Öğrenme güçlüğü olan çocukların diş çürüğü, ağız bakımı ve restorasyonlarının incelendiği bir sistematik derlemenin sonucunda; öğrenme güçlüğü olan ve olmayan çocukların süt dişlerinde ve daimi dişlerinde diş çürüğü karşılaştırması açısından kesin bir kanıt olmadığ 1 belirlenmiştir. Öğrenme güçlüğü olan çocukların alt gruplarında, Down sendromu hariç diğer çocukların diş çürüğü seviyesi açısından benzerlik gösterdiği, Down sendromlu çocukların daimi dişlerinde diş çürüğünün daha az olduğu belirtilmiştir (14). Down sendromlu bireylerde diş çürüğünün daha düşük görülmesinin nedenleri arasında; dişlerin diastemalı olması, dişlerin geç sürmesi, tükürük kimyasının farklı olması, hipodonti, oligodonti, mikrodonti görülmesi ve bruksizme bağlı olarak diş yüzeylerinin düzleșmesi yer almaktadır (15). $\mathrm{Bu}$ çalışmada, Down sendromlu bireylerin ortalama DMFT değerleri $(4,20 \pm 1,93)$; Ghaith ve ark. (16) tarafindan belirtilen değerlerden belirgin olarak daha yüksek, Jaber ve arkadaşlarının (11) çalışmasında çıkan değerlerden ise daha düşük çıkmıştır. Robertson ve arkadaşlarının (14) bulgularına karşıt olarak bu çalışmada Down sendromlu bireylerin daimi dişlerindeki diş çürüğü oranı, diğer öğrenim güçlüğü bulunan gruplardan daha yüksek bulunmuştur.
Otizmli çocuklar; yiyecekleri seçmeleri, ağızlarında yemek tutmaları, diş firçalamaya karşı direnç göstermeleri, diş muayenesi ve müdahalelerinde kooperasyon eksikliğgi göstermeleri nedeni ile yüksek çürük riski altındadırlar. Ancak otizmli bireylerde artmış çürük riski üzerine var olan kanıtların çelişkili sonuçları olduğu görülmektedir $(11,17)$. Bazı çalışmalarda otizmli çocukların diş çürüğü seviyesi açısından sağlıklı çocuklarla benzer ya da daha düşük oranlara sahip olduğu gösterilmiştir (18-20). Bu çalışmada otizmli çocukların diş çürüğü seviyeleri ile mental retardasyonu olan veya Down sendromlu bireylerin diş çürüğü seviyeleri arasında anlamlı bir fark bulunmamıştır. Bu çalışmaya dahil edilen otizmli bireylerin dft $(3,47 \pm 2,5)$ ve DMFT $(4,17 \pm 1,87)$ değerleri, Kuter ve ark. (21) (dft: 1,66 $\pm 2,07$; DMFT: $0,52 \pm 1,21$ ) ile Naidoo ve ark.'nın (22) (dft: 0,97; DMFT: 3,42 ) bulduğu değerlerden daha yüksek olduğu görülmektedir.

Down sendromu ve otizm dişında bir sendrom ile birlikte görülmeyen zihinsel engelli bireyler non-sendromik zihinsel engelli bireyler olarak da sınıflandırılmaktadırlar (23). Zihinsel engelli çocukların genel popülasyona göre daha zayıf ağız hijyenine sahip oldukları ve tedavi edilmemiş diş çürüğü sayısının daha fazla olduğu gösterilmiştir (24). Bunun sebebi olarak koordine kas hareketlerinde eksiklik, düşük anlama kapasitesi ve yönlendirmeleri takip etmede güçlük nedeni ile ağız hijyeni alışkanlıklarının yerine getirilememesi olduğu bildirilmektedir (25). Bu çalışmada zihinsel engelli çocukların dft $(3,64 \pm 2,47)$ ve DMFT $(4,15 \pm 1,90)$ skorları, Makkar ve ark.'nın (26) çalışmasından (sırası ile $0,77 \pm 1,33 ; 2,26 \pm 1,89$ ) daha yüksek bulunmuştur.

\section{Oklüzal Anomaliler}

Down sendromlu bireylerde sıklıkla oklüzal ve dentofasiyal anomalilere rastlanmakta ve bu anomaliler ağız fonksiyonlarında azalmaya ve durumlarının daha komplike bir hale gelmesine neden olmaktadır. Down sendromlu çocuklarda orta yüz bölgesinde gelişim geriliği, mandibular prognatizm, geniş ve protrüze dil nedeni ile sınıf III maloklüzyona daha sik rastlanmaktadır (15). Yapılan bir çalışmada Down sendromlu çocukların sahip oldukları ağı sağlığı bulguları arasında ebeveynlerini en çok maloklüzyonun olumsuz etkilediği görülmüştür (27). Bu çalışmada yer alan Down sendromlu birey sayısının az olmasına rağmen, aralarında en çok sınıf III maloklüzyona rastlanmıștır.

Otizmli çocuklarda maloklüzyonu değerlendiren çalışmalarda henüz tutarlı bir sonuç elde edilememiştir. $\mathrm{Bu}$ çocukların ön açık kapanış gibi belirli maloklüzyon özelliklerine daha fazla eğilim gösterdikleri ileri sürülmüştür. Yapılan araştırmalarda otizmli çocukların sağlıklı çocuklara göre örtülü kapanış, artmış overjet ve ön çapraz kapanış prevalansının daha yüksek olduğunu ancak bulguların istatistiksel olarak anlamlı olmadığ görülmüştür (28). Bu çalışmada otizmli çocukların \%80,95'inde Sınıf I çene kapanış ilişkisine rastlanmıştır. Otizmli bireylerde Sınıf I kapanış ilişkisi (nötral oklüzyon) görülme oranı, Down sendromlu bireylerden anlamlı derecede daha yüksek bulunmuştur.

Zihinsel engelli bireylerde maloklüzyon, estetik bakış açısı göz önüne alındığında bu bireylerin sosyal kabulünün önünde bir engel olarak yer almakta ve bu sorunun yanı sıra çocukların çiğneme ve yutma gibi oral 
fonksiyonlarını da etkilemektedir. Zihinsel engelli bireylerin ortodontik tedavi ihtiyaçlarının kapsamlı bir şekilde değerlendirildiği çalışmalara ihtiyaç duyulduğu belirtilmektedir (29). Çalışmamızda zihinsel engelli bireylerde sırası ile Sınıf I, Sınıf II ve Sınıf III çene ilişkisinin görüldüğü saptanmıştır.

\section{Dişlerde Aşınma}

Diş sert dokularında diş çürüğünden bağımsız olarak meydana gelen aşınmalar uzun dönemde ağız sağlığına olumsuz etki etmektedir. Kontrolsüz olarak devam eden dental aşınmalar sonucunda diş yüzeylerinde şiddetli madde kaybı, dişlerde hassasiyet, derin kapanış, kötü estetik görüntü ve etkilenen dişlerde dental apseler meydana gelmektedir (30).

Down sendromlu çocukların \%13,8 ile \%59'unda görülen gastroözefagal reflü ve kusma gibi gastrik disfonksiyonların dişlerde erozyona yol açtığ bildirilmiştir (40). Yapılan çalışmalarda Down sendromlu bireylerde sağlıklı bireylere göre erozyona daha sık rastlandığı belirtilmiştir (16).

Otizmin semptomlarının giderilmesinde sıklıkla reçete edilen, santral sinir sistemi uyarıcılar (metilfenidat), antihipertansifler (klonidin), antidepresanlar (fluloksetin), antikonvülsonlar (karbamazepin, valproat) ve antipsikotikler (olanzepin, risperidon) gibi bazı ilaçların olası yan etkilerinden biri de ağız kuruluğudur. Meydana gelen ağız kuruluğunun bu hastaların dişlerinde erozyon riskini artırdığı bildirilmiştir (31). Yapılan araştırmalara ilaç kullanımının dişlerde erozyon riskini artırabileceği belirtilmiş olmakla birlikte, bu çalışmada düzenli olarak ilaç kullanan özel bakım gereksinimi olan bireylerin dişlerinde aşınma görülme oranı ilaç kullanmayanlardan daha düşük olarak bulunmuştur. Engelli çocuklara ulaşmanın zorluğu ve dolayısıyla çalışmaya dahil edilen olgu sayısının sınırlı olmasının böyle bir sonucun ortaya çıkmasına neden olabileceği düşünülmektedir.

\section{Bruksizm}

Bruksizm; sıklıkla uyku problemleri, horlama ve obtrüktif uyku apnesi ile ilişkili olarak görülen bir parafonksiyondur (32). Etyolojisine göre primer ve sekonder bruksizm olarak sinıflandırılmaktadır. Nedenleri arasında kendine zarar verme, ilaç kullanımı ve kaslara ilişkin problemler de yer almaktadır (31). Sekonder bruksizme neden olan faktörlerden bir tanesi de antipsikotik ve kardiyoaktif ilaçların kullanımıdır (33). Diş yüzeylerinde aşınmaya, baş ağrısına, temporomandibular eklem disfonksiyonuna ve periodontal problemlere neden olabilmektedir (34). Literatürde öğrenme güçlüğü çeken çocuklarda ve genç erişkinlerde bruksizm prevalansının $\% 8$ ile \%31 arasında olduğu bildirilmiştir (35).

Down sendromlu çocuklarda rapor edilen bruksizm prevalans1 ise \%23 ile \%42 arasindadır $(32,36)$. Down sendromlu bireylerde obstrüktif uyku apnesi gibi uyku bozukluklarına ve bruksizme s1k rastlandığ bildirilmektedir (34).

Otizmli çocuklar üzerinde yapılan çalışmalarda, bruksizme, ağız açmada kisıtlılığa ve oklüzal uyumsuzluklara daha $\mathrm{sik}$ rastlandığı belirtilmiştir. Araştırmacılar, 3 yaşından önce özel eğitim görmeye başlayan otizmli çocuklarda, daha büyük yaşlarda özel eğitim görmeye başlayan otizmli çocuklara göre bruksizmin daha az görüldügüünü bildirmişlerdir (31).
İleri derecede zihinsel engeli olan bireylerde görülebilen bozulmuş oral motor fonksiyon ve zayıflamış kaslar çiğneme problemlerine neden olduğu ve yutkunmayı etkilediği bildirilmiştir. Kas koordinasyon bozukluğu sonucu bu hastalarda bruksizm ve konuşma bozukluğu da gelişmektedir (37).

$\mathrm{Bu}$ çalışmada ilaç kullanımı ile bruksizm arasında herhangi bir ilişki saptanmamıştır.

\section{Dental Travma}

Özel bakım gereksinimi olan çocuklarda dental travma sıklığı üzerine yapılmış sınırlı sayıda çalışma bulunmaktadır. Yapılan araştırmalarda dental travma prevalansının sağlıklı çocuklarda \%58,6 (38) oranında; özel bakım gereksinimi olan çocuklarda ise \%9,2 (39) oranında görülmüştür. Bu çalışmada otizmli çocuklarda (\%14) ve Down sendromlu çocuklarda (\%20) saptanan dental travma sıklığı Bagattoni ve ark.'nın (40) çalışmasından $(\% 30,4$ ve $\% 8,5)$ daha farklı, zihinsel engelli bireylerde ise aynı seviyede (\%21,62'ye \%20) bulunmuştur. Çalışmamızda en çok zihinsel engelli bireylerde dental travmaya rastlanmıştır.

\section{SONUÇ}

İyi bir ağız sağlığı, bebeklik döneminde ebeveynlerin ve/veya bakıcıların aktif desteğini içeren yardımcı bir ortamla başlamalıdır. Kişisel bakım ve sağlıklı bir yaşam tarzı iyi ağız sağlığına sahip olmak ve bunu sürdürmek için temeldir, ancak bunun özel bakım gereksinimi olan insanlar için daha zor olabildiği bilinmektedir. Özel bakım gereksinimi olan kişilerin yılda en az bir kez düzenli diş muayenesinin yapılması, ağız sağlığını izlenmesi ve daha kolay tedavi edebilmek adına erken bir aşamada ağız-diş hastalığının tanımlaması tavsiye edilmektedir. Ancak engelli bireylerde fiziksel, mental vb. yetersizliklerin mevcut olması, günlük hayatta karşılaşılan zorluklar, dental bakıma dair bilgi eksikleri nedeniyle ideal bir ağız sağlığının sağlanması daha güç hale gelmektedir. Ağız bakımını kendisi sağlayamayan bireylerde mutlaka yardımcı birinden destek alınması gerekmektedir. Periyodik diş hekimi muayenesini aksatılmamalı, bu sayede diyet ve diş firçalama gibi diğer sağlık davranışları hakkında zamanında ve uygun tavsiye ve destek alınması mümkün olmaktadır.

Engellilerin diş sağlığı hizmetlerine erişimlerinin zor olduğu ve sınırlı sayıda engelli bireye ulaşılabildiği düşünüldüğünde, gönüllü diş hekimi ekipleri tarafından engelli merkezlerine düzenli ziyaretlerin gerçekleştirilerek daha geniş bir kitleye gerekli önerilerin ve yönlendirmelerin yapılması ile bu gruptaki çocukların ağız sağlığına katkıda bulunulması önem taşımaktadır. Diş hekimliği kurumlarının bünyesine gönüllü etkinliklerin düzenlenmesinin teşvik edilmesi gerektiği düşünülmektedir.

Yazarların Katkıları: Fikir/Kavram: F.Z.A.; Tasarım: F.Z.A., M.K.; Veri Toplama ve/veya İşleme: C.A., Ö.B.Ç.; Analiz ve/veya Yorum: M.K.; Literatür Taraması: Y.K., C.A.; Makale Yazımı: Y.K., Ö.B.Ç.; Eleştirel İnceleme: Y.K., M.K.

\section{KAYNAKLAR}

1. Saravanakumar MS, Vasanthakumari A, Bharathan R. Oral health status of special health care needs children 
attending a day care centre in Chennai. Int J Students' Res. 2013; 3(1): 12.

2. Tufan İ, Arun Ö. Türkiye bilimsel ve teknik araştırma kurumu Türkiye özürlüler araştırması. 2. baskı. Ankara: DİE Matbaası; 2006.

3. Owens PL, Kerker BD, Zigler E, Horwitz SM. Vision and oral health needs of individuals with intellectual disability. Ment Retard Dev Disabil Res Rev. 2006; 12(1): 28-40.

4. Setiawati AD, Suharsini M, Budiardjo SB, Indiarti IS, Widyagarini A. Assessment of dental anxiety using braille leaflet and audio dental health education methods in visually impaired children. J Int Dent Med Res. 2017; 10(Special Issue): 441-4.

5. Petersen P, Baez R, Ramon J, World Health Organization. Oral Health surveys: basic methods. 5th edition. Geneva: WHO Press; 2013.

6. Angle EH. Classification of malocclusion. Dent Cosmos. 1899; 41: 350-75.

7. Beange HP. Caring for a vulnerable population. Med J Aust. 1996; 164(3): 159-60.

8. Gordon SM, Dionne RA, Snyder J. Dental fear and anxiety as a barrier to accessing oral health care among patients with special health care needs. Spec care Dent. 1998; 18(2): 88-92.

9. Shore S, Lightfoot T, Ansell P. Oral disease in children with Down syndrome: causes and prevention. Community Pract. 2010; 83(2): 18-22.

10. Deps TD, Angelo GL, Martins CC, Paiva SM, Pordeus IA, Borges-Oliveira AC. Association between dental caries and Down syndrome: a systematic review and meta-analysis. PLoS One. 2015; 10(6): e0127484.

11. Jaber MA. Oral Health Condition and Treatment Needs of a Group of UAE Children with Down Syndrome. Ibnosina J Med Biomed Sci. 2010; 2(2): 62-71.

12. Corder JP, Al Ahbabi FJS, Al Dhaheri HS, Chedid F. Demographics and co-occurring conditions in a clinic based cohort with Down syndrome in the United Arab Emirates. Am J Med Genet Part A. 2017; 173(9): 2395-407.

13. Moreira MJS, Schwertner C, Jardim JJ, Hashizume LN. Dental caries in individuals with D own syndrome: a systematic review. Int J Paediatr Dent. 2016; 26(1): 3-12.

14. Robertson MD, Schwendicke F, de Araujo MP, Radford JR, Harris JC, McGregor S, et al. Dental caries experience, care index and restorative index in children with learning disabilities and children without learning disabilities; a systematic review and meta-analysis. BMC Oral Health. 2019; 19(1): 146. doi: 10.1186/s12903-019-0795-4.

15. Macho V, Coelho A, Areias C, Macedo P, Andrade D. Craniofacial features and specific oral characteristics of Down syndrome children. Oral Heal Dent Manag. 2014; 13(2): 408-11.

16. Ghaith B, Al Halabi M, Khamis AH, Kowash M. Oral health status among children with Down syndrome in Dubai, United Arab Emirates. J Int Soc Prev Community Dent. 2019; 9(3): 232-9.

17. Altun C, Guven G, Akgun OM, Akkurt MD, Basak F, Akbulut E. Oral health status of disabled individuals attending special schools. Eur J Dent. 2010; 4(4): 361-9.

18. Fakroon S, Arheiam A, Omar S. Dental caries experience and periodontal treatment needs of children with autistic spectrum disorder. Eur Arch Paediatr Dent. 2015; 16(2): 205-9.

19. Vellappally S, Gardens SJ, Al Kheraif A-AA, Krishna M, Babu S, Hashem M, et al. The prevalence of malocclusion and its association with dental caries among 12-18-year-old disabled adolescents. BMC Oral Health. 2014; 14(1): 123-9.

20. Du RY, Yiu CKY, King NM, Wong VCN, McGrath CPJ. Oral health among preschool children with autism spectrum disorders: A case-control study. Autism. 2015; 19(6): 746-51.

21. Kuter B, Guler N. Caries experience, oral disorders, oral hygiene practices and socio-demographic characteristics of autistic children. Eur J Paediatr Dent. 2019; 20(3): 237-41.

22. Naidoo M, Singh S. The Oral health status of children with autism Spectrum disorder in KwaZulu-Nata, South Africa. BMC Oral Health. 2018; 18(1): 165-74.

23. Kaufman L, Ayub M, Vincent JB. The genetic basis of non-syndromic intellectual disability: a review. J Neurodev Disord. 2010; 2(4): 182-209.

24. Seirawan H, Schneiderman J, Greene V, Mulligan R. Interdisciplinary approach to oral health for persons with developmental disabilities. Spec Care Dent. 2008; 28(2): 43-52.

25. Chiurazzi P, Pirozzi F. Advances in understandinggenetic basis of intellectual disability. F1000Research. 2016; 5: 1-16.

26. Makkar A, Indushekar KR, Saraf BG, Sardana D, Sheoran N. A cross sectional study to evaluate the oral health status of children with intellectual disabilities in the National Capital Region of India (Delhi-NCR). J Intellect Disabil Res. 2019; 63(1): 319.

27. Scalioni F, Carrada CF, Abreu L, Ribeiro RA, Paiva SM. Perception of parents/caregivers on the oral health of children/adolescents with Down syndrome. Spec Care Dent. 2018; 38(6): 382-90.

28. Fontaine-Sylvestre C, Roy A, Rizkallah J, Dabbagh B, dos Santos BF. Prevalence of malocclusion in Canadian children with autism spectrum disorder. Am J Orthod Dentofac Orthop. 2017; 152(1): 38-41.

29. Rao D, Hegde S, Naik S, Shetty P. Malocclusion in individuals with mental subnormality-a review. Oral Heal Dent Manag. 2014; 13(3): 786-91.

30. Hyder M, Tanboga I, Kalyoncu I, Arain H, Marks L. Are Down syndrome children more vulnerable to tooth wear? J Intellect Disabil Res. 2019; 63(11): 1324-33.

31. Önol S, Kırzıoğlu Z. Evaluation of oral health status and influential factors in children with autism. Niger $\mathrm{J}$ Clin Pract. 2018; 21(4): 429-35.

32. Ella B, Ghorayeb I, Burbaud P, Guehl D. Bruxism in movement disorders: a comprehensive review. J Prosthodont. 2017; 26(7): 599-605.

33. Berry RB, Brooks R, Gamaldo CE, Harding SM, Marcus CL, Vaughn B V. assm.org [Internet]. Illinois: The American Academy of Sleep Medicine; 2012 [Updated: 2015; Cited: 2020 Apr 24] Avaliable from: 
https://aasm.org/resources/pdf/scoring-manualpreface.pdf

34. Stores G, Stores R. Sleep disorders and their clinical significance in children with Down syndrome. Dev Med Child Neurol. 2013; 55(2): 126-30.

35. Manfredini D, Serra-Negra J, Carboncini F, Lobbezoo F. Current concepts of bruxism. Int J Prosthodont. 2017; 30(5): 437-8.

36. Miamoto CB, Pereira LJ, Ramos-Jorge ML, Marques LS. Prevalence and predictive factors of sleep bruxism in children with and without cognitive impairment. Braz Oral Res. 2011; 25(5): 439-45.

37. Aşıcı N, Doğan C, Odabaş ME, Alaçam A. Zihinsel Engelli Çocuklarda Diş Erozyonu ve DMFT Değerlendirilmesi-Pilot Çalışma. Acta Odontol Turcica. 2003; 20(2): 15-20.

38. Marcenes W, Zabot NE, Traebert J. Socio-economic correlates of traumatic injuries to the permanent incisors in schoolchildren aged 12 years in Blumenau, Brazil. Dent Traumatol. 2001; 17(5): 218-22.

39. Ferreira MCD, Guare RO, Prokopowitsch I, Santos MTBR. Prevalence of dental trauma in individuals with special needs. Dent Traumatol. 2011; 27(2): 113-6.

40. Bagattoni S, Sadotti A, D’Alessandro G, Piana G. Dental trauma in Italian children and adolescents with special health care needs. A cross-sectional retrospective study. Eur J Paediatr Dent Off J Eur Acad Paediatr Dent. 2017; 18(1): 23-6. 